\title{
Impact of Adversity Quotient on Stress Levels of Middle-Level Managers of Non-Governmental Organisation (NGO) Sector
}

\author{
C.S.N. Somaratne*, L.N.A.C. Jayawardena ${ }^{1}$ and B.M.K. Perera \\ Postgraduate Institute of Agriculture \\ University of Peradeniya \\ Sri Lanka
}

\begin{abstract}
Non-governmental organisations (NGO) around the world operate under highly dynamic and volatile conditions creating workplace adversities that lead to stress. There is a demand for employees who can effectively handle adverse situations under minimal stress levels. Adversity quotient is the measure of the ability of an individual to bounce back and cope with adverse situations encountered. This study was aimed at investigating the relationship between levels of stress and adversity quotient of middle-level managers employed in the Sri Lankan NGO sector. The study also examined the difference in levels of adversity quotient due to the demographic factors such as gender and age. Data were collected from 200 samples through self-administered questionnaires, and were analysed using correlation, independent-samples t-test, one-way ANOVA, and hierarchical regression tests. Findings revealed a significant association between adversity quotient and stress of middle-level managers. Age was found to be significantly influencing adversity quotient, however, gender did not record such influence. The study also found that the adversity quotient and age as significant predictors of stress among the middle-level managers in NGO sector.
\end{abstract}

Keywords: Adversity quotient, middle-level managers, non-governmental organisations, stress

\section{INTRODUCTION}

Among numerous causes of stress, organisational, environmental, and personal factors are identified as major contributors (Matteson and Ivancevich, 1999; Cook and Hunsaker, 2001). The changing nature of organisational environment has created a wide range of developments, challenges, and risks for organisations. Contemporary organisations, both profit and not-for-profit face demanding challenges in such highly volatile environmental conditions. Organisations are under pressure to work out new measures to meet the challenges they are faced with, for their survival ensuring business continuity and growth. At present occupational stress has become a global issue affecting all categories of employees in all societies and countries (Haider and Supriya, 2007). A major portion of stressors available in the organisational context occurs related to task, role, and interpersonal demands at work (Fox et al., 1993). Similarly, uncertainties in the environment, which occur due to changes in the economic, political, and technological spheres, can lead to organisational changes creating more issues for employees (Robbins, 2013). Apart from the typical stressors at

\footnotetext{
1 Department of Agricultural Extension, Faculty of Agriculture, University of Peradeniya, Sri Lanka.

* Corresponding author: chamelisomaratne@yahoo.com
} 
work, the challenges, experiences, and problems that people encounter in other areas of life, especially the factors in the employees' personal lives spill over to the job (Ornelas and Kleiner, 2003). Under these circumstances, the actions and decisions employees make are bound by certain limitations of knowledge, skills, capacities, assistance, and resources. When an individual perceives this discrepancy between the challenging conditions and own capacities to fulfil the requirement, stress come into play (Topper, 2007).

Causes that lead to stress could be a change, demand, constraint, or a challenge. Topper (2007) defines stress as a person's psychological and physiological response to the perception of demands and challenges. Ornelas and Kleiner (2003) define occupational stress as a mismatch between organisational demands and individual employee capacities. Stress is a much-researched concept with more focus on its causes, mediators, and outcomes (Deary et al., 1996). Stress in any sector has become a growing concern since employees encounter a wide range of adversities both at work and in personal life. Stress has been identified as subjective (Sathasivam, et al., 2015). A phenomenon perceived as stressful by one individual will not make the same level of impact on another. As stated by Phoolka and Kaur (2012), people are different in their mental capacities. Therefore, the way in which the adversities or stressful situations are handled by each individual is unique to the person.

The individual differences of people in the capacity to bounce back from adversities, is emphasised under the concept of Adversity Quotient as an indicator of the ability of an individual to cope with adversities (Stoltz, 1997). AQ consists of four dimensions represented by the acronym CORE. These aspects are Control, Ownership, Reach, and Endurance. Control refers to the degree of influence or control one has over a particular situation or life (Stoltz, 1997). Those who are relatively strong in this aspect tend to be proactive in adverse situations and are capable of turning adversity into opportunity (Stoltz, 2000). Such individuals will exert more effort with higher levels of resilience and perseverance in successfully attaining assigned tasks (Hung and Chin, 2013). Ownership refers to the degree of accountability one feels to improve the outcome of the adverse situation encountered. It is the extent to which one feels responsible to improve the current situation. Reach refers to the degree to which one perceives the adversity reaches into other areas of life. It is the perception of the individual on the extent to which the adverse events can influence other areas of life. Endurance refers to a person's perception of the duration the adversity and the cause of adversity will last. Those with high AQ find adversities as temporary and have solutions to overcome them. Such individuals are optimistic and energetic in coping with adverse events (Stoltz, 2000). These four pillars of AQ suggest that higher levels of these cognitive dimensions contribute to better performances in the face of adversity (Hung and Chin, 2013).

According to Phoolka and Kaur (2012), several concepts such as resilience, longevity, performance, persistence, and response to change are found to be predictable with respect to AQ level of a person. AQ research has already been conducted on samples such as teachers, students, managers, psychologists, hospital staff, entrepreneurs, insurance agents, information technology staff, and political leaders. AQ has proved to improve performance levels, leadership styles and practices, resilience, promotions, retention, optimism and commitment to change.

The Non-Governmental Organisational sector has been identified as one of the highly stressful sectors by employees (Armstrong et al., 2009). As per the views of Trautmann et al. (2007), many NGOs around the world are undercapitalised in responding to growing demands of civil society, competing for funding sources as well as for experienced and 
qualified staff to function in an increasingly competitive and complex market economy. Harrison (2013) highlights the fact that employees of the NGO sector are engaged in highly demanding, complex, and difficult work, often in relatively poor conditions. This is no exception to the Local (LNGO) and International NGOs (INGO) operating in Sri Lanka. NGOs which are foreign-based and operating in multiple countries are commonly known as International NGOs while organisations that operate only at the national level are known as Local NGOs. All the NGOs operating in Sri Lanka are registered under the Voluntary Social Services Organisations Act of 1980 as amended by the Voluntary Social Services Organisations Act No. 8 of 1998 and operate under the purview of the National Secretariat for Non-Governmental Organisations.

Regardless of the growth in the NGO sector during the war and tsunami periods, currently there is a substantial decline in terms of funding and number of NGOs operating in Sri Lanka (De Silva, 2016). This is mainly due to recognition of Sri Lanka as a middle-income country, donors' attention towards man-made and natural disasters (e.g., Syrian refugee crisis), and political influence (De Silva, 2016; Akurugoda et al., 2017).

According to McMurray et al. (2010) research on occupational stress in non-profit organisations are relatively less compared to profit and public sector organisations. Occupational stress is a much researched about concept in a variety of contexts (Pasca and Wagner, 2011) compared to AQ which is considered as a new paradigm gaining research interest in the organisational context (Phoolka and Kaur, 2012; Ng, 2013). Limited empirical studies have been conducted on AQ (Song and Woo, 2015). Especially, the impact of AQ on stress is less discussed (Shen, 2014). Literature becomes further limited when it comes to studies on AQ in the Sri Lankan NGO sector.

As mentioned earlier, the Sri Lankan NGO sector has undergone massive changes during the past few years. Research has found that workplace adversities can impact the overall stress level of people especially leading to negative workplace outcomes such as low satisfaction and performance, and high turnover (Elangovan, 2001; Tian and Fan, 2014). Therefore, under such circumstances, NGO employees are inevitably left with complexities both in professional and personal life. Considering the changing environment in the NGO sector and limited research in this sector, the current study identified the importance of investigating $\mathrm{AQ}$ and stress in the Sri Lankan NGO sector.

The literature shows that some studies on AQ have found the influence of personal factors such as age and gender (Paramanandam and Shwetha, 2013) while some other studies show contrasting results (Bantang et al., 2013). Understanding difference in AQ due to personal factors is important especially from an organisational perspective for various reasons including training and development. Therefore, further research is required to overcome inconsistency of findings in this area.

Considering above limitations in the literature, the objectives of current study were; to examine the influence of demographic factors (i.e., age and gender) on stress of NGO sector middle-level managers, to examine the association between AQ and its sub-dimensions (control, ownership, reach, and endurance) and stress of NGO sector middle-level managers and to examine the contribution of $\mathrm{AQ}$ and demographic factors (i.e. age, gender) to the stress of NGO sector middle-level managers. 


\section{MATERIALS AND METHODS}

A positivistic approach was employed for the research study. A sample of 200 middle-level managers from 24 LNGOs and 12 INGOs was selected using a two-stage stratified random sampling method. Employees of all the levels in the NGOs could not be selected for the survey since they were dispersed around the country engaged in different projects. The study only selected middle-level managers of both LNGOs and INGOs. The respondents were selected from NGOs registered in Colombo having headquarters in Colombo that may also have outstation operations in the country. As the first stage NGOs in the Colombo District were identified, and then NGOs in the Colombo Divisional Secretariat were identified. Accordingly, a total of 96 registered NGOs including 32 INGOs (Stratum 1) and 64 LNGOs (Stratum 2) were recognised. Proportion to the ratio of 1:2, 12 INGOs and 24 LNGOs were randomly selected for the study. The unit of analysis of this study was middle-level managers. Due to unavailability of statistics on the number of middle-level managers employed in these organisations, all the middle-level managers in the randomly selected 36 organisations were surveyed. Data were collected through a survey questionnaire using established research instruments that measure AQ and perceived stress. The scale designed by Stoltz (2000) was used to examine the levels of AQ of employees having 20 scenarios representing its four dimensions. The Perceived Stress Scale (PSS-14) by Cohen (1983) was used to examine the level of perceived stress among respondents. Data were analysed using SPSS 21. After ensuring that there were no missing values or outliers, the normality of data were tested. The z-scores of kurtosis and skewness were used to measure the distribution of data.

\section{RESULTS AND DISCUSSION}

A total of 200 samples were analysed and the sample consisted of 141 men and 59 women. There were 73 percent of men in LNGOs and 68 percent of men in INGOs. Average age of middle-level managers was 39 years. Respondents recorded a mean value of 134.75 from a maximum score of 200 with a Standard Deviation (SD) of 26.7 for AQ. A mean value of 26.86 from a maximum value of 56 with a standard deviation of 10.30 was scored for stress. As indicated in Table 1, z-scores of skewness and kurtosis for all the variables were within the accepted range. Therefore, it was considered that all the variables were approximately normally distributed.

As indicated in Table 1, Cronbach's Alpha values for both instruments were found reliable.

Table 1. Descriptive statistics and scale reliability of $A Q$ and stress

\begin{tabular}{llllll}
\hline Variable & Mean & $\begin{array}{l}\text { Standard } \\
\text { Deviation } \\
\text { (SD) }\end{array}$ & $\begin{array}{l}\text { Skewness } Z \text { - } \\
\text { Score }\end{array}$ & $\begin{array}{l}\text { Kurtosis } \\
\text { Score }\end{array}$ & $\begin{array}{l}\text { Cronbach's } \\
\text { Alpha }\end{array}$ \\
\hline $\begin{array}{l}\text { Adversity } \\
\text { Quotient }\end{array}$ & 134.75 & 26.75 & 0.54 & -2.04 & 0.91 \\
\hline Stress & 26.86 & 10.30 & 0.05 & -2.00 & 0.91 \\
\hline
\end{tabular}

\section{Hypothesis Testing}

The first hypothesis investigated whether there was a difference in AQ due to demographic factors. First hypothesis consists of two parts. 
Hypothesis 1a: There is a relationship between the level of AQ and the gender of NGO sector middle-level managers

Hypothesis $1 \mathrm{a}_{0}$ : There is no relationship between the level of AQ and the gender of NGO sector middle-level managers

An Independent-samples t-Test was used to identify whether there was a significant difference in the AQ levels among male and female middle-level managers. As indicated in Table 2, homogeneity of variances was fulfilled as the test value of 0.83 was greater than the level of significance $(p>0.05)$. The t-test results indicated that male middle-level managers have a higher AQ level. However, as the p-value was above the level of significance there was no difference between the two groups. Due to this reason the null hypothesis could not be rejected.

\section{Table 2. Influence of gender on AQ}

\begin{tabular}{|c|c|c|c|c|c|c|}
\hline & \multicolumn{2}{|c|}{ Mean } & \multirow{2}{*}{$\begin{array}{c}\text { Mean } \\
\text { Difference }\end{array}$} & \multirow{2}{*}{$\begin{array}{l}\text { Test } \\
\text { Value }\end{array}$} & \multirow[t]{2}{*}{$p$-value } & \multirow{2}{*}{$\begin{array}{l}\text { Levene's Test } \\
\text { for Equality of } \\
\text { Variances } \\
\text { (Sig.) }\end{array}$} \\
\hline & $\begin{array}{l}\text { Women } \\
(\mathbf{n}=59)\end{array}$ & $\begin{array}{l}\text { Men } \\
(n=141)\end{array}$ & & & & \\
\hline $\begin{array}{l}\text { Adversity } \\
\text { Quotient }\end{array}$ & 129.97 & 136.75 & -6.78 & -1.64 & 0.10 & 0.83 \\
\hline
\end{tabular}

Results indicated that AQ of male middle-level managers was not significantly different from that of the females. This confirmed previous findings of Huijuan (2009) and Bantang et al. (2013) who proposed that gender has no significant influence on the level of AQ of an individual. A possible assertion is that AQ is a mental capacity that extends beyond the masculine and feminine traits of people.

The second part of the first hypothesis tested whether there was a difference in the AQ level due to age.

Hypothesis $1 \mathrm{~b}$ : There is a relationship between the level of AQ and the age of NGO sector middle-level managers

Hypothesis $1 b_{0}$ : There is no relationship between the level of AQ and the age of NGO sector middle-level managers

A one-way ANOVA was conducted to identify whether there was a significant difference among the mean values of different age groups. As indicated in Table 3, the assumption of homogeneity of variances was violated, as assessed by Levene's test for equality of variances $(p<0.05)$. Therefore, results of the Welch ANOVA test were used to identify the differences among age group categories. The results (Table 3) indicated that AQ was significantly different among age groups (Welch's $F=78.60, p<0.05$ ). The Games-Howell Post-hoc test revealed that there were significant mean differences between all the age categories.

This study revealed that the level of AQ of middle-level managers has increased with the increase in age. The results indicated that the age group 25 to 34 years had the lowest AQ levels while the age group 55 to 64 years had the highest levels of AQ. This finding was consistent with the findings of Paramanandam and Shwetha (2013) who found increase of AQ with age. Shen (2014) also found age to have a significant effect on AQ. It can be assumed that employees in higher age categories with more exposure and experience have developed AQ abilities. Those experiences and encounters have possibly made them more 
resilient and better able to cope with adversity, and thus superior to that of those in younger age groups. According to Stoltz (1997), the more hardships a person experiences, the more that person learns how to deal with them.

Table 3. Influence of age on AQ

\begin{tabular}{|c|c|c|c|c|c|c|c|c|}
\hline & \multicolumn{4}{|c|}{ Age (Mean) } & \multirow{2}{*}{$\begin{array}{c}\text { Welch } \\
\text { Statistic } \\
(F)\end{array}$} & \multirow[t]{2}{*}{ df } & \multirow[t]{2}{*}{$p$ Value } & \multirow{2}{*}{$\begin{array}{l}\text { Levene's } \\
\text { Test for } \\
\text { Equality of } \\
\text { Variances } \\
\text { (Sig.) } \\
\end{array}$} \\
\hline & $\begin{array}{l}25-34 \\
(n=64)\end{array}$ & $\begin{array}{l}35-44 \\
(n=95)\end{array}$ & $\begin{array}{l}45-54 \\
(n=32)\end{array}$ & $\begin{array}{l}55-64 \\
(n=9)\end{array}$ & & & & \\
\hline Adversity & & & & & & & & \\
\hline Quotient & 118.62 & 134.25 & 156.87 & 176.00 & 78.60 & 3 & 0.00 & 0.03 \\
\hline
\end{tabular}

The second hypothesis investigated the association between AQ and its sub-dimensions (control, ownership, reach, and endurance) and stress.

Hypothesis 2: There is an association between AQ and its sub-dimensions and stress of NGO sector middle-level managers

Hypothesis $2_{0}$ : There is no association between AQ and its sub-dimensions and stress of NGO sector middle-level managers

To test the second hypothesis, the association between employees' AQ and its subdimensions and stress levels, a Pearson Product-Moment correlation analysis was conducted. The results (Table 4) indicated that there was a strong negative association $(r=-0.823)$ between perceived stress and AQ levels of respondents. All the sub-dimensions of AQ also showed a strong negative relationship: control $(r=-0.683)$, Ownership $(r=-0.772)$, Reach $(r=-0.683)$, and Endurance $(r=-0.668)$.

Table 4. Association between Adversity Quotient and Stress

\begin{tabular}{ll}
\hline Parameter & Stress \\
\hline Control & $-0.683^{* *}$ \\
Ownership & $-0.772^{* *}$ \\
Reach & $-0.683^{* *}$ \\
Endurance & $-0.668^{* *}$ \\
Adversity Quotient & $-0.823^{* *}$ \\
\hline Note. ${ }^{* *} p<0.01$ &
\end{tabular}

The strong negative association $(r=-0.823)$ between stress and AQ implied that employees with higher levels of AQ have a low level of stress. This result made the theoretical assertions of the study tenable. One possible reason for this association could be that, managers who have developed AQ skills are able to overcome adversities that can result in lower levels of stress. When they have higher levels of control, they tend to be proactive in facing adverse situations and are capable of turning adversity into opportunity. This is evident in the findings of the study that show a strong negative relationship ( $r=-0.683)$ with stress. The negative association of ownership $(r=-0.772)$ implies that middle-level managers with high AQ levels tend to own or feel accountable to improve the adverse situations and face them with responsibility. They also tend to make each situation a learning opportunity and change their strategy of dealing with stressful situations accordingly. Individuals with 
high AQ levels do not let adversities to reach other areas of life and they face stressful events with a mind-set that limit the negative effects to that particular situation. This is confirmed by the negative relationship between reach and stress $(r=-0.683)$. Similarly, as indicated by the negative relationship between endurance and stress $(r=-0.668)$, individuals with high AQ tend to find adversities as temporary and of having solutions to overcome them.

As stated by Hung and Chin (2013), higher levels of AQ will result in better performance in the face of adversity. This can be witnessed in the results of this study where higher AQ levels accompanied lower levels of stress.

The third hypothesis of the study investigated whether AQ and demographic factors predict the variance in stress.

Hypothesis 3: Adversity quotient, along with gender, and age have a relationship with the stress levels of NGO sector middle-level managers

Hypothesis $3_{0}$ : Adversity quotient, along with gender, and age do not have a relationship with the stress levels of NGO sector middle-level managers

To address the third hypothesis, hierarchical regression was used. AQ was used as the predictor variable in the first block, and gender and age were entered in the second block in order to predict the variance in stress. To test for multicollinearity, the tolerance values were used. Tolerance values for AQ, gender, and age were 0.62, 0.98, and 0.61, respectively. Hence, multicollinearity was not an issue. Findings verified homoscedacity of data and there were no outliers. As indicated in Table 5 , the $R^{2}$ of 0.67 shows that AQ predicts $67 \%$ variance in stress. The addition of gender and age has increased the predictability power of the model to $69 \%\left(R^{2}=0.69\right)$. This shows that the model has a strong fit with the data. The standard beta coefficients of the final model (model 2) show that one point increase in AQ will cause 0.72 decrease of standard deviations in stress. Similarly, one unit increase in age will cause 0.14 decrease of standard deviations in stress. The effect of gender was not significant in this study. Phoolka and Kaur (2012) claimed that AQ is useful to predict persistence, resilience, and longevity in the face of adversities. Similarly, this study found that AQ is able to predict variance in stress.

Table 5. Hierarchical Regression Results

\begin{tabular}{lccr}
\hline Variable & Beta & SE Beta & Standard Beta \\
\hline Step 1 & & & \\
(Constant) & 69.51 & 2.13 & \\
Adversity Quotient & -0.31 & 0.02 & $-0.82 * *$ \\
Step 2 & & & \\
(Constant) & 73.94 & 2.50 & \\
Adversity Quotient & -0.28 & 0.01 & $-0.72 * *$ \\
Gender & -1.10 & 0.90 & -0.05 \\
Age & -0.22 & 0.07 & $-0.14 * *$ \\
\hline Note. $R^{2}=0.67$ for Step $1, R^{2}=0.69$ for Step $2, * 00.05, * * p<0.01$ &
\end{tabular}

Results indicated that the variance in stress can be explained by AQ and age of respondents. Therefore, it is evident that there is a strong inter-linkage between AQ level and stress. This implies that higher AQ levels lead to lower stress levels. This hypothesis also revealed age as a factor that can predict the variance in stress. Gender as a factor revealed no such effect. Nasurdin et al. (2005) found a similar effect of gender and age on predicting the variance in stress. 


\section{CONCLUSIONS}

This study claimed that AQ or the ability of coping and responding to adversities play a significant role in coping with stressors or adversities encountered at work. This study has theoretical and practical implications. This study has contributed to the current literature by revealing a negative relationship between AQ and stress. It was found that higher level of AQ is associated with lower levels of stress. Findings related to influence of demographic factors, age and gender indicated mixed results in the literature, therefore, the findings of this study are important. The study found that AQ level increases as the age of a person increases. However, gender indicated no influence on AQ. Meanwhile, AQ and age were found to explain the variance in stress of middle-level managers. Based on the findings, NGOs can utilise AQ in their human resource management strategies for hiring and recruitment to attract individuals who can better deal with adversities and can operate with minimal levels of stress. The findings also imply the need for promoting AQ training and development programmes to develop the ability of middle-level managers to cope and surmount adversities faced at work. This study has focused only on the middle-level managers of the NGO sector and therefore future studies can focus on different levels of management in various organisations.

\section{REFERENCES}

Akurugoda, I.R., Barrett, P. and Simpson, A. (2017). Different levels of NGO engagement and reactions of the government: Assessing the Sri Lankan experience. J. Asian Dev. 3(2), 103-119.

Armstrong, L., Bluitt-Fisher, J., Lopez-Newman, L., Paul, D.R. and Paul, K.R. (2009). Nonprofits in crisis: How to retain employees in the nonprofit sector. [Online]. [Accessed on 06.07.2017]. Available at http: // digitalscholarship.unlv.edu/ cgi/

viewcontent.cgi?article $=1811 \&$ context $=$ thesesdissertations

Bantang, F.A., Bianes, N.S., Caguinging, M.P., Estrekka, P.C. and Macanlalay, C.M. (2013). The relationship of personal characteristics and job satisfaction to adversity quotient of police officers in Manila police district. [Online]. [Accessed on 10.05.2017]. Available at https:// www.peaklearning.com /documents/ PEAK_GRI_caguingin.pdf

Cohen, S., Kamarck, T. and Mermelstein, R. (1983). A global measure of perceived stress. J. Health Soc. Behav. 385-396.

Cook, C.W. and Hunsaker, P.L. (2001). Management and Organisational Behaviour. 3rd Ed. McGraw Hill, New York.

Deary, I.J., Blenkin, H., Agius, R.M., Endler, N.S., Zealley, H. and Wood, R. (1996). Models of job-related stress and personal achievement among consultant doctors. Br. J. Psychol. 87(1), 3-29.

De Silva, D. (2016). Dilemma of continuous funding of Sri Lankan NGOs and not-for-profit organisations. [Online]. [Accessed on 14.07.2017]. Available at http://www.sundaytimes.lk /160424/business-times/dilemma-of-continuous-funding-of-sri-lankan-ngos-and-not-forprofit-organisations-190357.html 
Elangovan, A.R. (2001). Causal ordering of stress, satisfaction and commitment, and intention to quit: a structural equations analysis. Leadership Org. Dev. J. 22(4), 159-165.

Field, A. (2009). Discovering statistics using SPSS. Sage Publications, London

Fox M.L., Dwyer D.J. and Ganster D.C. (1993). Effects of stressful job demands and control of physiological and attitudinal outcomes in a hospital setting, Acad. Manag. J. 289-318.

Haider, Y. and Supriya, M.V. (2007). Career management: A view through stress window. Int. Rev. Business Res. Papers. 3(5), 182-192.

Harrison, L.J. (2013). Feeling the heat: workers' experiences of job stress in the Victorian community services sector [Online]. [Accessed on 10.07.2017]. Available at http://vuir.vu. edu.au/21792/1/ Lorraine\%20Jessie\%20Harrison.pdf

Huijuan, Z. (2009). The adversity quotient and academic performance among college students at St. Joseph's college Quezon city. [Online]. [Accessed on 10.05.2017]. Available at https:// www.peaklearning.com/ documents/PEAK_GRI_huijuan.pdf

Hung, M.L. and Chin, P.L. (2013). Psychological contract breach and turnover intention: the moderating roles of adversity quotient and gender. Soc. Behav. Pers. 41(5), 843-859.

Matteson, M.T. and Ivancevich, J.M. (1999). Organisational Behaviour and Management. 5th Ed. McGraw Hill, New York.

McMurray, A., Pirola-Merlo, A., Sarros, J. and Islam, M. (2010). Leadership, climate, psychological capital, commitment, and wellbeing in a non-profit organisation. Leadership Org. Dev. J. 31(5), 436-457.

Nasurdin, A.M., Ramayah, T. and Kumaresan, S. (2005). Organisational stressors and job stress among managers: The moderating role of neuroticism. Sing. Mgt. Rev. 27(2), 63.

Ng, T. (2013). Organisational Resilience and Adversity Quotient of Singapore Companies. Int. Proc. Econ. Dev. \& Res. 65, 81.

Ornelas, S. and Kleiner, B.H. (2003). New development in managing job related stress, J. Equal Opportunities Int. 2(5), 64-70.

Paramanandam, P. and Shwetha, R. (2013). Adversity Quotient (AQ) as a predictor of job satisfaction. Int. J. Glob. Business Mgt. \& Res. 1(2), 27.

Pasca, R. and Wagner, S.L. (2011). Occupational stress in the multicultural workplace. J. Immigr. Minor Health. 13(4), 697-705.

Pediwal, G.L. (2011). Excessive stress and its impact on employee behavior. J. Glob. Econ. 1(1), 13-40.

Phoolka, E.S. and Kaur, N. (2012). Adversity quotient: A new paradigm to explore. Cont. Business Stud. 3(4), 67-78. 
Robbins, S.P. and Judge, T.A. (2013). Organisational Behaviour. 15th Ed. Prentice Hall, United States.

Sathasivam, K.V., Malek, M.D.H.A. and Abdullah, A.F. (2015). Job Stress among Malaysian Managers: The moderating role of coping methods. Int. J. Soc. Sci. Stud. 3(3), 75-86.

Shen, C.Y. (2014). The relative study of gender roles, and job stress and adversity quotient. J. Glob. Business Mgt. 10(1), 19.

Song, J.H. and Woo, H.Y. (2015). A study on AQ (Adversity Quotient), job satisfaction and turnover intention according to work units of clinical nursing staffs in Korea. Indian J. Sci. Technol. 8(S8), 74-78.

Stoltz, P.G. (1997). Adversity quotient: Turning obstacles into opportunities. John Wiley \& Sons, New York.

Stoltz, P.G. (2000). Adversity quotient @ work: Make everyday challenges the key to your success - putting the principles of AQ into action. Wiley, New York.

Tian, Y. and Fan, X. (2014). Adversity quotients, environmental variables and career adaptability in student nurses. J. Vocat. Behav. 85(3), 251-257.

Topper, E.F. (2007), Stress in the library, Journal of New Library. 108(11/12), 561-564.

Trautmann, K., Maher, J.K. and Motley, D.G. (2007). Learning strategies as predictors of transformational leadership: the case of nonprofit managers. Leadership Org. Dev. J. 28(3), 269-287. 